Original Article

\title{
DEVELOPMENT OF A DENSITOMETRIC HIGH-PERFORMANCE THIN-LAYER CHROMATOGRAPHIC METHOD FOR THE QUANTITATIVE ANALYSIS OF URSOLIC ACID IN THE LEAVES OF SPECIES OF GENUS TECOMA AND TABEBUIA OF BIGNONIACEAE FAMILY
}

\author{
KALYANI A. KEDAR ${ }^{a, b, *}$, SANJAY. R. CHAUDHARIc, AVANAPU S. RAO ${ }^{d}$
}

aP. E. Society's Modern College of Pharmacy, Nigdi, Pune Maharashtra 411044, bJawaharlal Nehru Technological University (JNTU), Hyderabad, Andra Pradesh, 500072, India, cAmrutvahini College of Pharmacy Amrutnagar, Sangamner SK, Tal-Sangamner, Dist Ahmednagar, Maharashtra 422608, India, dBhaskar Pharmacy College, Yeknapally, Moinabad (Mandal), R. R. (Dt), Hyderabad 500075, India Email: kk_pharma20@rediffmail.com

Received: 21 Oct 2016 Revised and Accepted: 07 Dec 2016

\section{ABSTRACT}

Objective: A simple and sensitive high-performance thin-layer chromatographic (HPTLC) method was developed for the quantification of ursolic acid in the leaves of three species of genus Tecoma (Tecoma gaudichaudi DC, Tecoma capensis (Thunb.) Lindl, Tecoma stans (L.) Juss. ex Kunth) and genus Tabebuia (Tabebuia rosea Bertol) belong to family Bignoniaceae.

Methods: Chromatography was performed on Silica gel 60 F254 precoated HPTLC Plates with optimised mobile phase pet ether: ethyl acetate: formic acid (7:3:0.5, v/v/v). The plate was derivatized with p-anisaldehyde reagent and scanned at $540 \mathrm{~nm}$. The developed method was found to give a compact spot for ursolic acid at $\mathrm{R}_{\mathrm{f}}$ value $0.43 \pm 0.01$. The method was validated using International Council for Harmonization (ICH) guidelines, including linearity, precision, accuracy, and robustness.

Results: Ursolic acid was found to be present in four species, i.e., Tecoma gaudichaudi DC $(1.48 \% \mathrm{w} / \mathrm{w})$, Tecoma capensis (Thunb.) Lindl. $(0.79 \% \mathrm{w} / \mathrm{w})$, Tecoma stans (L.) Juss. Ex Kunth $(1.11 \% \mathrm{w} / \mathrm{w})$, Tabebuia rosea (Bertol.) $(1.13 \% \mathrm{w} / \mathrm{w})$. A good linearity relationship was found to be (200-1400ng band-1) with a correlation coefficient $\left(\mathrm{r}^{2}\right)$ value of 0.9946 with ursolic acid. Limit of detection and limit of quantification was considered to be $40.66,123.21 \mathrm{ng}$ per band respectively. The developed method was found to be accurate and precise with $1.32 \%, 1.19 \%$ (\%RSD) for interday and intraday precision. The accuracy of the method was performed by recovery studies at three different concentration levels, and the average percentage recovery was found to be $98.05 \%$ for ursolic acid.

Conclusion: The proposed method for the quantitation of ursolic acid was found to be reproducible and simple.

Keywords: Bignoniaceae, Tecoma, Tabebuia, Ursolic acid, High-performance thin layer chromatography

(C) 2017 The Authors. Published by Innovare Academic Sciences Pvt Ltd. This is an open access article under the CC BY license (http://creativecommons.org/licenses/by/4. 0/) DOI: http://dx.doi.org/10.22159/ijpps.2017v9i2.15802

\section{INTRODUCTION}

Bignonia Linn (Bignoniaceae) is a monotypic genus of woody climbers, native to North America and mostly grown for ornament in the tropics of the old world [1]. Bignoniaceae family was having 100 genera and more than 750 plant species observed in various tropical regions of India. Known numbers of this family are Bignonia, Tecoma, Catalpa, Tabebuia and Jacaranda. These are succulent herbs, shrubs, stem sometimes reduced to a rhizome or tuber. Numerous species of this family are observed as poisonous to leeches [2]. In Charak, Sushruta, the root, bark, stem and leaf of some species of Bignoniaceae family is useful for snake bite, the stem and wood for scorpion sting. In Bangladesh whole plant of Tecoma gaudichaudi DC use of a remedy for diabetes and infertility problems [3].

From all secondary metabolite's pentacyclic triterpenes, are an important group of it considered as lupenyl, ursanyl, betulenyl or oleanyl. They are presented in plant species as the form of aglycone's saponin triterpenoids [4-5]. Previous reports state that species of Bignoniaceae family show the presence of promising active constituents such as tannins, flavonoids, triterpenes, alkaloids, carbohydrates, etc. [6]. Ursolic acid was pentacyclic triterpene reported in several plant species such as Alstonia scholars R. Br., Diospyros melanoxlon, Holoptelea integrifolia [7-9]. Ursolic acid was reported to for its various biological activities such as antiinflamatory, antidiabetic and can target several steps of cancer development. Thus, being a promising tool for the treatment and chemoprevention of cancer [10-12].

The phytochemical analysis of various species of Bignoniaceae family was not studied so far hence; the following research deals with to carry an out analysis of ursolic acid by high-performance thin layer chromatography in four species of Bignoniaceae family (Tecoma gaudichaudi DC, Tecoma capensis (Thunb.) Lindl, Tecoma stans (L.) Juss. Ex Kunth, Tabebuia rosea (Bertol.) Berto).

\section{MATERIALS AND METHODS}

\section{Plant materials}

All four species of Bignoniaceae family, i.e. Tecoma gaudichaudi DC (Sample 1), Tecoma capensis (Thunb.) Lindl. (Sample 2), Tecoma stans (L.) Juss. Ex Kunth (Sample 3), Tabebuia rosea (Bertol.) (Sample 4) were collected from a different area of Pune district (Maharashtra), and the plants were authenticated at Botanical Survey of India, Pune with reference no. BSI/WRC/Iden./2015/576 on dated 18-12-2015. The specimen voucher number is KALKTEG1, KKA-2, KKA-3, KKA-1 specimens of plants were deposited at the Botanical Survey of India, Pune and department of Pharmacognosy, Modern College of Pharmacy, Nigdi, Pune.

Chemicals and reagents

Ursolic acid was purchased from Sigma-Adrich (USA), analytical grade solvents, reagents, silica gel 60 F254 precoated HPTLC Plates $(20 \times 20 \mathrm{~cm})$ were purchased from Merck (Germany).

\section{HPTLC instrumentation and experimental conditions}

Chromatographic analysis was done on $20 \times 10 \mathrm{~cm}$ HPTLC Silica gel F254 plates (Merck, Germany). Samples of extracts and standards were applied as band length $8 \mathrm{~mm}$ wide and $8 \mathrm{~mm}$ apart by the Camag Linomat V sample applicator. The application rate of the sample on the plate was $150 \mathrm{nl} / \mathrm{s}$. The plates were developed in 
previously saturated $(20 \times 10 \mathrm{~cm})$ twin trough glass chamber at room temperature. Analysis carried out at $540 \mathrm{~nm}$ in absorbance remission mode by TLC scanner III (Camag, Muttenz, Switzerland) and win CATS version 1.4.0 software (Camag, Muttenz, Switzerland) was used in this study. Microsoft excel was also used to treat data statistically.

\section{Plant material and Preparation of extracts}

Ethyl acetate extracts of four species of Bignoniaceae family, i.e. Tecoma gaudichaudi DC (Sample 1), Tecoma capensis (Thunb.) Lindl. (Sample 2), Tecoma stans (L.) Juss. Ex Kunth (Sample 3), Tabebuia rosea (Bertol.) (Sample 4) were prepared by weighing $500 \mathrm{gm}$ of air dried powdered material, and extraction was carried out by soxhlet extraction assembly for $6 \mathrm{~h}$. The solution was filtered, concentrated and use for HPTLC analysis of each sample was subjected to soxhlet extraction for $6 \mathrm{~h}$.

\section{Preparation of a calibration curve}

A stock solution of ursolic acid (standard) was prepared by dissolving $10 \mathrm{mg}$ in $100 \mathrm{ml}$ methanol. For calibration 2, 4, 6, 8, 10, $12,14 \mu \mathrm{l}$ standard solutions were applied to HPTLC plate in the range 200-1400ng per band.

\section{Method development}

Initially, different mobile phases were used for chromatogram development from this best resolution was observed in the selected pet ether: Ethyl acetate: Formic acid (7:3:0.5 v/v/v) solvent system, gives a compact peak of standard ursolic acid and standard in ethyl acetate leaf extract of samples Tecoma gaudichaudi DC (Sample 1), Tecoma capensis (Thunb.) Lindl. (Sample 2), Tecoma stans (L.) Juss. Ex Kunth (Sample 3), Tabebuia rosea (Bertol.) (Sample 4). Dry TLC plate derivative with a p-anisaldehyde reagent, heat plate on $105{ }^{\circ} \mathrm{C}$ and observed separation of bands it helps in analysis of ursolic acid in Extracts [13]. The analysis was done at $540 \mathrm{~nm}$.

\section{Method validation}

The analytical method was validated for linearity, precision, accuracy, specificity, limit of detection (LOD) and limit of quantitation (LOQ) according to International Council for Harmonization [14].

\section{Linearity range}

For determining the linearity range of standard ursolic acid, a series of spots of different volumes $(2,4,6,8,10,12,14 \mu \mathrm{l})$ was applied to get the 200-1400ng quantity of ursolic acid per band, respectively. The plate was scanned at $540 \mathrm{~nm}$, and the curve was prepared with respect to area vs. amount per band.

\section{Precision and accuracy}

Precision studies were carried out to show the reproducibility of the proposed developing method. Repeatability was determined by preparing eight replicates of the same concentration (500ng band ${ }^{-1}$ ) of the sample. The intraday precision study was carried out by preparing the same concentration of a standard compound, and it can be analyzing at three different times in a day. The same procedure was followed for three different days to determine interday precision. The results were reported as \% RSD.

\section{Specificity}

The specificity of the method was determined by analyzing the standard drug and sample. The presence of ursolic acid in Tecoma gaudichaudi DC (Sample 1), Tecoma capensis (Thunb.) Lindl. (Sample 2), Tecoma stans (L.) Juss. Ex Kunth (Sample 3), Tabebuia rosea (Bertol.) (Sample 4) were confirmed by comparing $\mathrm{R}_{\mathrm{f}}$ of the sample with a standard. (fig. 4-9)

\section{Limit of detection and quantitation}

In order to determine the limit of detection (LOD) and limit of quantitation (LOQ) was calculated based on standard deviation (SD) and slope $(\mathrm{S})$ of the calibration curve at levels approaching the LOD according to formula. $\{\mathrm{LOD}=3.3(\mathrm{SD} / \mathrm{S})$ and $\mathrm{LOQ}=10(\mathrm{SD} / \mathrm{S})\}$.

\section{Robustness}

Robustness was studied in triplicate at $500 \mathrm{ng}^{\text {band }}{ }^{-1}$ by making a small variation in optimised method parameters. Variation in composition of the mobile phase, chamber saturation time and activation of HPTLC plates. The results were examined in terms of relative standard deviation (\%RSD) and standard error of the peak area. Mobile phase prepared by the solvent system such as pet ether: ethyl acetate: formic Acid in different concentration (7: 3: 0.5v/v/v), (7.5: 2.5: $0.5 \mathrm{v} / \mathrm{v} / \mathrm{v}), \quad(6.5: 3.5: 0.5 \mathrm{v} / \mathrm{v} / \mathrm{v})$ was used for chromatographic analysis. Duration of saturation time change during chromatograph development $20 \pm 5 \mathrm{~min}$ (15, 20 and $25 \mathrm{~min}$ ) respectively. The plate was activated at $110{ }^{\circ} \mathrm{C}$ for $10 \pm 5 \min (5,10$, $15 \mathrm{~min}$ ) and analyzed at $540 \mathrm{~nm}$. By introducing small changes into chromatographic method and \% RSD was obtained less than $2 \%$, proved the robustness of the proposed method.

\section{Assay of ursolic acid}

Standard ursolic acid and the test sample were spotted on HPTLC plate. The percentage of ursolic acid present in test samples $(1,2,3$ and 4) was determined by using a calibration curve of the standard. Thereby, the content of ursolic acid was calculated for species of Tecoma and Tabebuia genus.

\section{RESULTS AND DISCUSSION}

\section{Plant material and preparation of extracts}

Ethyl acetate extracts of four species of Bignoniaceae family, i.e. Tecoma gaudichaudi DC (Sample 1), Tecoma capensis (Thunb.) Lindl. (Sample 2), Tecoma stans (L.) Juss. Ex Kunth (Sample 3), Tabebuia rosea (Bertol.) (Sample 4) were prepared by soxhlet extraction assembly and the yield was $8.5 \%, 4.0 \%, 5.75,6.2 \% \mathrm{w} / \mathrm{w}$ respectively and used for HPTLC analysis.

\section{Method development}

The developed mobile phase was found to be effective in the separation of components in samples Tecoma gaudichaudi DC (Sample 1), Tecoma capensis (Thunb.) Lindl. (Sample 2), Tecoma stans (L.) Juss. Ex Kunth (Sample 3), Tabebuia rosea (Bertol.) (Sample 4) and shows compact and sharp peaks of standard (ursolic acid) and standard in the four samples from selected mobile phase under specific saturation time (fig. 3 and 4). The identity of the standard in the sample extracts was confirmed by the same $\mathrm{R}_{\mathrm{f}}$ value $(0.43 \pm 0.01)$ (fig. 5, 6, 7, 8 and 9) for ursolic acid in standard and samples.

\section{Method validation}

The linearity of standard ursolic acid was validated by the linear regression equation and correlation coefficient. The calibration curve of ursolic acid was found to be linear in the range of 200-1400 ng band-1 (table 1 and fig. 2). Regression equation and value of $\mathrm{r}^{2}$ for the reference compound were observed as $\mathrm{Y}=861.4+4.931 \mathrm{X}$ and 0.9946 respectively; improved method shows good linearity and resolution (table 1). The mean values with SD of the slope were 4.931 and intercept value of SD was 861.4. Inter-day and intra-day precision $(n=8)$ for ursolic acid were carried out at $500 \mathrm{ng}^{\text {band }}{ }^{-1}$ and found to be $1.32 \%$ and $1.19 \%$ (\%RSD) respectively. Good precision was observed from developed method for ursolic acid. Limit of detection (LOD) and limit of quantitation (LOQ) was considered to be $40 \mathrm{ng}$ and $123.21 \mathrm{ng}^{-1}$ band $^{-1}$ respectively (table 1 ). This indicated the sensitivity of the instrument for the quantitation of the compound. The accuracy of the method was studied by performing recovery studies at 3 levels of ursolic acid. Pre-analyzed samples were spiked with $50 \%, 100 \%$ and $150 \%$ of the standard ursolic acid and analysed by the proposed HPTLC method. The experiment was conducted three times the percentage recovery at three different levels of ursolic acids was found to be $98.13,98.23$, $98.46 \%$ respectively (table 3 ). Robustness was studied in triplicate at $500 \mathrm{ng}^{\text {band }}{ }^{-1}$ by making a minor variation in optimised method parameters such as the variation in the composition of the mobile phase, chamber saturation time, plate activation time. The minimal value of SD and relative standard deviation (\% RSD) was obtained indicate that method was robust (table 4). 


\section{Assay of ursolic acid}

The developed mobile phase is useful for the quantitation and identification of ursolic acid in samples Tecoma gaudichaudi DC (Sample 1), Tecoma capensis (Thunb.) Lindl. (Sample 2), Tecoma stans (L.) Juss. Ex Kunth (Sample 3), Tabebuia rosea (Bertol.) (Sample 4). Ursolic acid standard was quantified by using developed mobile phase pet ether: ethyl acetate: formic acid $(7: 3: 0.5 \mathrm{v} / \mathrm{v} / \mathrm{v})$.

The ethyl acetate extracts of all four samples 1, 2, 3 and 4 observed some common $R_{f}$ value $0.43,0.5,0.6,0.9$ from this 0.43 noted for the presence of ursolic acid compare with standard (fig. $3 \mathrm{~A}-\mathrm{F}$ ). From the HPTLC chromatogram, all the four samples of the Bignoniaceae family i.e. sample 1 (Tecoma gaudichaudi DC), sample 2 (Tecoma capensis Thunb. Lindl). Sample 3 (Tecoma stans (L.) Juss. Ex Kunth), sample 4 (Tabebuia rosea (Bertol.) were found to contain ursolic acid by comparing with $\mathrm{R}_{\mathrm{f}}$ value of the standard (fig. 5, 6, 7, 8 and 9).
As per literature, ursolic acid has been estimated by using HPTLC in several plants from this some plant species are Alstonia scholars R. Br., Diospyros melanoxlon [7-8]. The ursolic acid content was observed as $0.302 \%$ and $0.122 \% \mathrm{w} / \mathrm{w}$ in Holoptelea integrifolia methanolic and hexane fraction respectively [9]. In some studies, the series of imine and phthalic acid derivatives of ursolic acid have been synthesised for antiinflammatory and anti-cancer potential.

So need to find out the rich source of ursolic acid containing medicinal plants [15]. The outcome of study includes quantitative analysis of ursolic acid by densitometric high-performance thin layer chromatography, from observation the content of ursolic acid in the Tecoma gaudichaudi DC $(1.48 \% \mathrm{w} / \mathrm{w})$, Tecoma capensis (Thunb.) Lindl. $(0.79 \% \mathrm{w} / \mathrm{w})$, Tecoma stans (L.) Juss. Ex Kunth $(1.11 \% \mathrm{w} / \mathrm{w})$, Tabebuia rosea (Bertol) $(1.13 \% \mathrm{w} / \mathrm{w})$ respectively from the calibration curve.

Table 1: Method validation parameters for the quantitation of ursolic acid by HPTLC

\begin{tabular}{ll}
\hline Parameters & Results \\
\hline Range of linearity $(\mu \mathrm{g} / \mathrm{ml})$ & $2-14$ \\
Regression of equation & $\mathrm{Y}=861.4+4.931 * \mathrm{X}$ \\
Correlation coefficient $\left(\mathrm{r}^{2}\right)$ & 0.9946 \\
LOD $(\mathrm{ng} / \mathrm{band})$ & 40.66 \\
$\mathrm{LOQ}(\mathrm{ng} / \mathrm{band})$ & 123.21 \\
\hline
\end{tabular}

Table 2: Interday and intraday precision of HPTLC $(n=8)$

\begin{tabular}{|c|c|c|c|c|c|c|}
\hline \multirow{2}{*}{ Amount (ng/band) } & \multicolumn{3}{|l|}{ Interday precision } & \multicolumn{3}{|l|}{ Intraday precision } \\
\hline & Mean $^{\mathrm{a}}$ area & SD & \%RSD & Meanaarea & SD & \%RSD \\
\hline $\begin{array}{l}\text { Ursolic acid } \\
500\end{array}$ & 2747.81 & 36.39 & 1.32 & 2991.29 & 35.78 & 1.19 \\
\hline
\end{tabular}

aMean of eight determinations.

Table 3: Accuracy (recovery study) determined for the TLC-densitometric method

\begin{tabular}{|c|c|c|c|c|}
\hline$\%$ of standard spiked to the sample & Theoretical content ( $\mu \mathrm{g} / \mathrm{band})$ & Experimental content $(\mu \mathrm{g} / \mathrm{band})$ & $\%$ mean a recovery & $\begin{array}{l}\text { RSD } \\
\text { (\%) }\end{array}$ \\
\hline 50 & 1734.8 & 1702.35 & 98.13 & 1 \\
\hline 100 & 1984.8 & 1949.66 & 98.23 & 1.07 \\
\hline 150 & 2234.8 & 2200.38 & 98.46 & 1.64 \\
\hline
\end{tabular}

aMean of three determinations

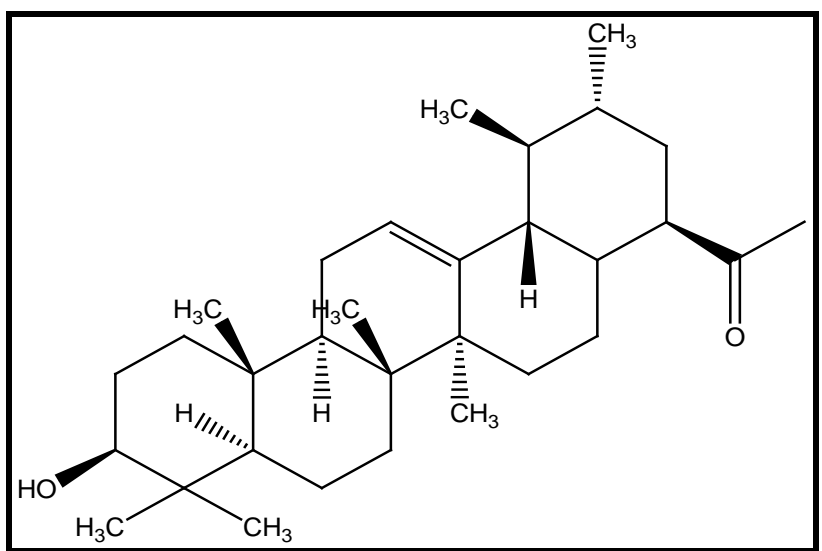

Fig. 1: Structure of ursolic acid

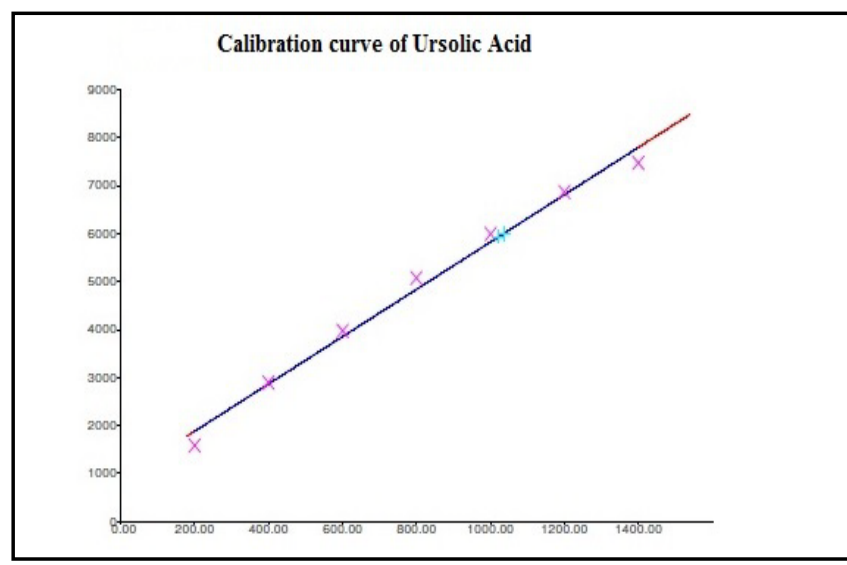

Fig. 2: Calibration curve of standard ursolic acid at $540 \mathrm{~nm}$ 
Table 4: Robustness study for the HPTLC method

\begin{tabular}{|c|c|c|c|c|}
\hline \multirow[t]{2}{*}{ Factors } & \multicolumn{4}{|c|}{ Chromatographic changes } \\
\hline & Level & Peak area $^{a}$ & SD & \%RSD \\
\hline Mobile phase composition & $( \pm 5)$ & & & \\
\hline $7.5: 2.5: 0.5$ & +5 & 3172.75 & 35.75 & 1.13 \\
\hline $7: 3: 0.5$ & 0 & 3016 & 39.97 & 1.32 \\
\hline $6.5: 3.5: 0.5$ & -5 & 3754.32 & 71.58 & 1.90 \\
\hline Saturation time & $( \pm 5)$ & & & \\
\hline 15 & +5 & 2991.29 & 52.21 & 1.74 \\
\hline 20 & 0 & 3217.75 & 47.10 & 1.46 \\
\hline 25 & -5 & 3779.33 & 66.50 & 1.75 \\
\hline Activation of TLC plate & $( \pm 5)$ & & & \\
\hline 5 & +5 & 3028.79 & 40.24 & 1.32 \\
\hline 10 & 0 & 3230.25 & 47.49 & 1.47 \\
\hline 15 & -5 & 3816.83 & 43.34 & 1.13 \\
\hline
\end{tabular}

aMean of three determinations

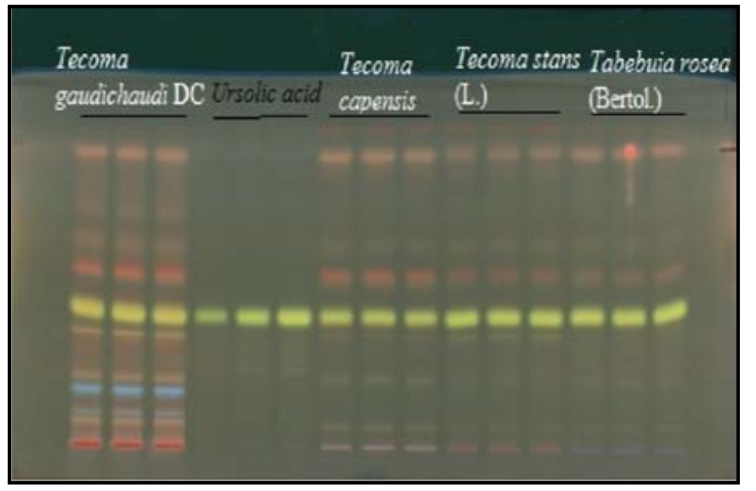

Fig. 3: Picture of developed TLC plate derivatized with panisaldehyde reagent at $540 \mathrm{~nm}$; mobile phase: pet ether: ethyl acetate: formic acid (7: 3: 0.5, v/v/v)

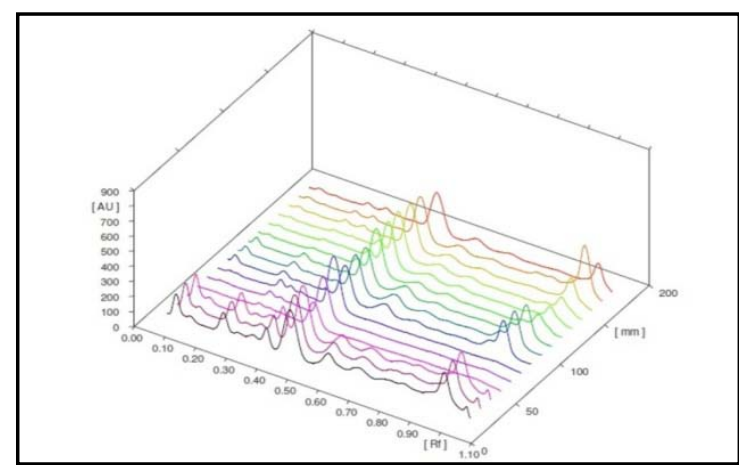

Fig. 4: 3D display of all tracks at $540 \mathrm{~nm}$; mobile phase: pet ether: ethyl acetate: formic acid (7: $3: 0.5, \mathrm{v} / \mathrm{v} / \mathrm{v})$

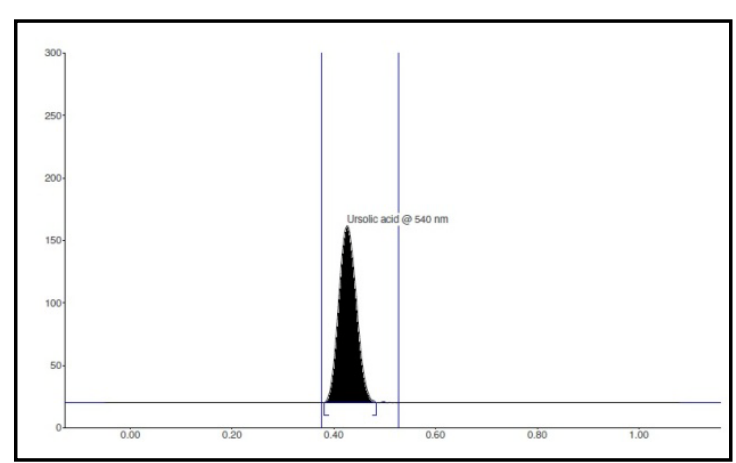

Fig. 5: Chromatogram of standard ursolic acid (500ng spot ${ }^{-1}$ ), peak $1\left(R_{\mathrm{f}}=0.43\right)$ at $540 \mathrm{~nm}$

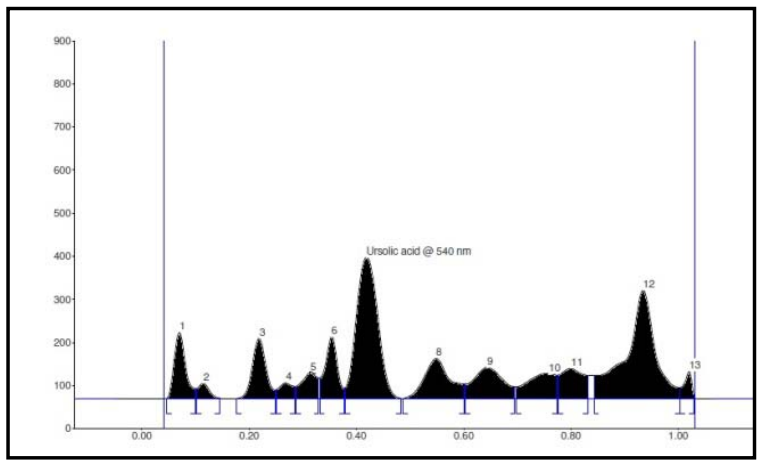

Fig. 6: Chromatogram of Ethyl acetate extract of leaf of Tecoma gaudichaudi DC (Sample 1) at $540 \mathrm{~nm}$

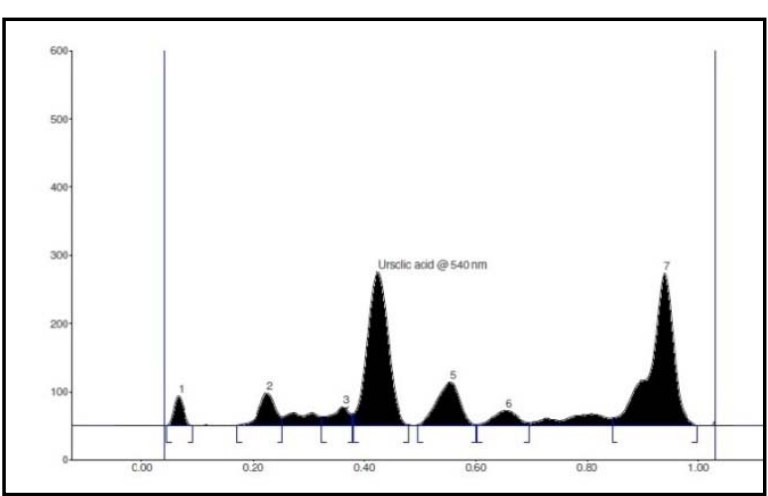

Fig. 7: Chromatogram of Ethyl acetate extract of leaf of Tecoma capensis (Thunb.) Lindl. (Sample 2) at $540 \mathrm{~nm}$

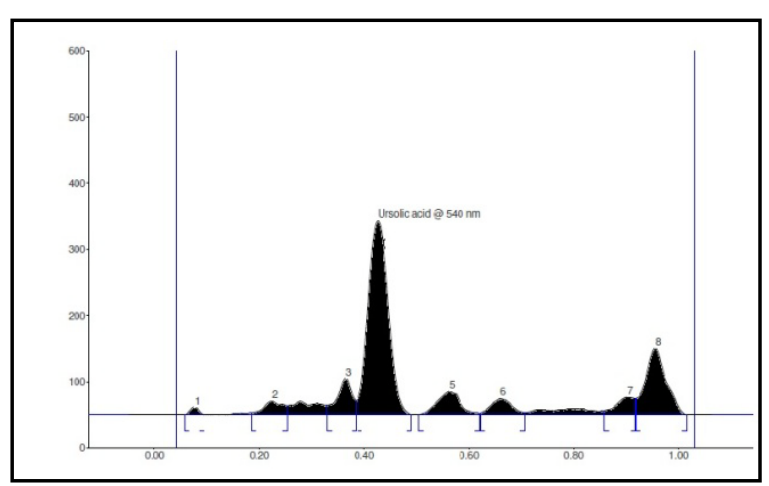

Fig. 8: Chromatogram of Ethyl acetate extract of leaf of Tecoma stans (L.) Juss. Ex Kunth (Sample 3) at 540 nm 


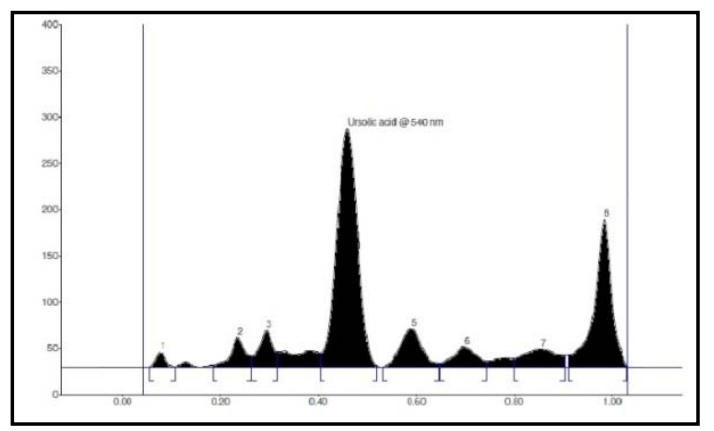

Fig. 9: Chromatogram of Ethyl acetate extract of leaf of Tabebuia rosea (Bertol.) (Sample 4) at $540 \mathrm{~nm}$

\section{CONCLUSION}

In present study HPTLC method was developed and validated for the determination of ursolic acid in Tecoma gaudichaudi DC (Sample 1), Tecoma capensis (Thunb.) Lindl. (Sample 2), Tecoma stans (L.) Juss. Ex Kunth (Sample 3), Tabebuia rosea (Bertol.) (Sample 4) leaf extracts, which shows $1.48 \% \mathrm{w} / \mathrm{w}, 0.79 \% \mathrm{w} / \mathrm{w}, 1.11 \% \mathrm{w} / \mathrm{w}$ and $1.13 \% \mathrm{w} / \mathrm{w}$ respectively. The proposed method was found to be simple, accurate, specific and robust for the analysis of ursolic acid in crude drug sample. So these studies shade on chromatographic analysis of four species of Bignoniaceae family. Based on these results leaves of Tecoma gaudichaudi DC (Sample 1), contain higher ursolic acid as compared to other species. So concentrated fractions or extract of leaves of Tecoma gaudichaudi DC is a rich source of ursolic acid and may be more useful for formulations.

\section{ACKNOWLEDGMENT}

Authors are thankful to Botanical Survey of India (BSI), Pune, BCUD Savitribai Phule Pune University, Jawaharlal Nehru Technological University, Hyderabad (JNTUH) and Modern college of Pharmacy for providing necessary assistance.

\section{CONFLICTS OF INTERESTS}

There are no conflicts of interest

\section{REFERENCES}

1. Anonymous. The wealth of India: raw materials, New Delhi Publications and Information Directorate, C.S.I.R; 2003.

2. Kirtikar KR, Basu BD. Indian Medicinal plants, International Book distributors Dehradun; 1999.
3. Rahmatullah M, Samarrai W, Rownak J, Shahnaz RSZUM, Nasima. An ethnomedicinal, pharmacological and phytochemical review of some Bignoniaceae family plants and a description of bignoniaceae plants in folk medicinal uses in Bangladesh. Adv Natr Appl Sci 2010;4:236-53.

4. Connolly JD, Hill RA. Triterpenoids. Natu Prod Rep 2000;17:463-82.

5. Allouche Y, Beltrán G, Gaforio JJ, Uceda M, Mesa MD. Antioxidant and antiatherogenic activities of pentacyclic triterpenic diols and acids. Food Chem Toxi 2010;48:2885-90.

6. Choudhary S, Datta S, Talukdar AD. Phytochemistry of the family bignoniaceae-a review. Assam Univ J Sci Technol Biol Environ Sci 2011;7:145-50.

7. Shetty P, Mangaonkar K, Sane RT. HPTLC determination of ursolic acid in Alstonia scholaris $\mathrm{R}$. Br J Planer ChromatoModern TLC 2007;20:65-8.

8. Raut K, Dash B, Singh R. HPTLC quantification and antimicrobial activity of ursolic acid from Diospyros melanoxylon. J Planer Chromato-Modern TLC 2012;25:320-5.

9. Dixit P, Pal M, Upreti D. Comparative studies on the analytical and antioxidant activities of the medicinally important stem bark of Holoptelea integrifolia. J Planer Chromato-Modern TLC 2014;27:162-5.

10. Liu J. Pharmacology of oleanolic acid and ursolic acid. J Ethnoparmacol 1995;49:57-68.

11. Salvador JAR, Leal ASM, Santos RC. In: Pentacyclic Triterpenes as Promising Agents in Cancer. Salvador JAR. editor. Nova Science Publishers, Inc; New York; 2010.

12. Novotny L, Vachalkova A, Biggs D. Ursolic acid: an antitumorigenic and chemopreventive activity. Neoplasma 2001;48:241-6

13. Wagner H, Bladt S. Plant drug analysis. 2nd ed. Springer-Verlag Berlin and Heidelberg; 1996.

14. International Council for Harmonization (ICH) HARMONISED TRIPARTITE GUIDELINE. Validation of analytical procedures: Methodology; 2005. p. 1-13.

15. Shrikant B, kirti L. Synthesis and characterization of new imine and pthalic acid derivatives of ursolic acid. Int J Pharm Pharm Sci 2014;10:560-4.

\section{How to cite this article}

- Kalyani A Kedar, Sanjay R Chaudhari, Avanapu S Rao. Development of a densitometric high-performance thin-layer chromatographic method for the quantitative analysis of ursolic acid in the leaves of species of genus Tecoma and tabebuia of the bignoniaceae family. Int J Pharm Pharm Sci 2017;9(2):109-113. 